\title{
RETRACTED ARTICLE: Improving Case-Based Ethics Training: How Modeling Behaviors and Forecasting Influence Effectiveness
}

\author{
Lauren N. Harkrider • Alexandra E. MacDougall • \\ Zhanna Bagdasarov • James F. Johnson • \\ Michael D. Mumford • Shane Connelly • \\ Lynn D. Devenport
}

Received: 2 December 2012/Accepted: 16 March 2013/Published online: 1 April 2013

(C) Springer Science+Business Media Dordrecht 2014

The authors have advised the Co-Editors of Science and Engineering Ethics that the article noted above must be withdrawn from publication. The University of Oklahoma's Institutional Review Board conducted a review of the study after online publication had occurred, concluding that, for administrative reasons, the data could not be used outside of reporting to the granting agency. They deferred judgment on whether the publication should be retracted to the Provost's office. The Provost's office held that publication of an article requires authors to make the data publicly available and hence recommended retraction.

L. N. Harkrider $(\bowtie)$

Kenexa, an IBM Company, 3010 Gaylord Parkway, Frisco, TX 75034, USA

e-mail: Lauren.Harkrider@us.ibm.com

A. E. MacDougall · Z. Bagdasarov · J. F. Johnson ·

M. D. Mumford · S. Connelly $\cdot$ L. D. Devenport

Department of Psychology, University of Oklahoma, Norman, OK, USA 